\title{
The prevalence of depression and related factors in diabetic patients referred to Rafsanjan diabetes center, Iran, 2016
}

\author{
Shafiepour MR, MD ${ }^{1}$, Bidaki R, MD², Hasibi E, Medical Student ${ }^{3}$, Mokhtaree MR, MSc ${ }^{4 *}$ \\ 1- Assistant Prof., Dept of. Internal Medicine, Rafsanjan University of Medical Sciences, Rafsanjan, Iran. 2- Associate Prof., \\ Research Center of Addiction and Behavioral Sciences, Diabetes Research Center, Shahid Sadoughi University of Medical \\ Sciences, Yazd,Iran. 3- Medical Student, Rafsanjan University of Medical Sciences, Rafsanjan, Iran 4- Msc of Educational \\ Psychology, Rafsanjan University of Medical Sciences, Rafsanjan, Iran.
}

\begin{abstract}
Received: September 2016, Accepted: December 2016

Background: The prevalence of diabetes mellitus (DM) is increasing, and thus, its mental consequences, such as depression, have an increasing trend. The goal of the present study was the determination of the prevalence of depression and some of its related factors in patients with type II DM who referred to the Diabetes Center of Rafsanjan, Iran, in the year 2016.

Materials and Methods: For this purpose, 194 patients with DM under care in the Diabetes Clinic of Ranfanjan University of Medical Sciences, Iran, were selected via simple random sampling method and filled a demographic form and the Beck Depression Inventory (BDI). Data were analyzed using chi-squared test.

Results: In this study, $67 \%, 24.7 \%, 6.2 \%$, and $2.1 \%$ of the participants had no depression symptoms, mild depression, moderate depression, and severe depression. There was significant difference between the frequency of different depression severities based on age $(\mathrm{P}<0.001)$, duration since disease diagnosis or treatment $(\mathrm{P}<0.001)$, occupation $(\mathrm{P}=0.011)$, education $(\mathrm{P}<0.001)$, and type of treatment.

Conclusions: The rate of depression in patients with DM is relatively high and women, people with lower level of education, and the elderly, and homemakers are at greater risk which signifies the necessity of psychological and psychiatric consultation.
\end{abstract}

Keywords: Diabetes Mellitus, Depression, Age, Sex

\section{Introduction}

Diabetes mellitus (DM) is one of the most prevalent diseases in human societies, and despite medical advances, the prevalence of this disease has not only not been decreased, but is increasing every day (1). Type I DM is a metabolic disorder and its main characteristic is lack of production and secretion of insulin. Its cause is an autoimmune disorder in beta cells of pancreatic islets of Langerhans (2). The most common age of onset of DM type $I$ is adolescence (3).

Type II DM or non-insulin-dependent DM is more common in adults of above 30 years of age. In this type of DM, insulin-relates glucose control is inefficient. In fact, either the pancreas does not secrete enough insulin or the secreted insulin does not sufficiently control blood glucose levels (4). The prognosis of DM among patients who have exhibited DM complications is not favorable and their mortality rate is high (5). Today, the mortality rate among patients with DM due to ketoacidosis and infection is decreasing, but due to cardiovascular and renal complications is significantly increasing (2). DM influences different aspects of the patient's life such as psychological, physical, economic, and social aspects, family life, and sexual performance (2). Chronic DM complications and the resulting decreased life expectancy and death

\footnotetext{
* Corresponding author: Mohammad Reza Mokhtaree, Rafsanjan University of Medical Sciences, Rafsanjan, Iran.

E-mail: mrmokhtaree@yahoo.com
} 
impose a high financial load on the individual, their family, and society, and affect the quality of life (QOL) of the individual and their family (6).

Depression is one of the most common psychological disorders in patients with DM (7). Depression symptoms include weight change, appetite change, and disruption in sleeping hours which if combined with symptoms caused by DM, the depression caused by DM is diagnosed clinically (8). In cases of mild DM, even without evident cerebrovascular events and recurring hypoglycemic attacks, some level of central nervous system (CNS) performance disorder is present. This complication first manifests itself as a mild cognitive disorder, and then, with the passage of time and increase in severity, it develops into depression (9). Vision loss due to diabetic retinopathy, repeated hospitalizations, and sexual dysfunctions are other factors which cause depression in diabetic patients (10). Depression in these patients can have a significant effect on the prognosis of DM. Some studies have shown that lack of diagnosis and treatment of depression worsens the prognosis in patients (11). This disorder has problematic symptoms and it is accompanied with the negative views of society and labeling of the afflicted person, which threaten the identity of individuals and increase their negative emotions (12).

Psychological disorders in patients with DM can have a negative effect on controlling blood sugar (13) and this indicates the importance of paying more attention to behavior and treatment of depression among patients with DM (14).

DM is an important and prevalent disease which, if not controlled, is accompanied with cardiovascular, renal, optical, neural, and psychological problems such as depression. Depression has an extensive influence on individual, social, and economic aspects of life, and therefore, it is of utmost importance. Awareness of the prevalence of diseases and their related factors, especially chronic diseases, in an area is a key point in the improvement of the quality and quantity of the provided health services in that area. This issue, in addition to human benefits, has large economic benefits due to preventing many diseases and disorders. Therefore, the aim of the present study was to determine some of the causes of depression in patients with type II DM referring to Rafsanjan Diabetes Center, Iran, in the year 2016.

\section{Materials and Methods}

The statistical population of this descriptive study included patients with DM referring to Rafsanjan Diabetes Center in the year 2016 $(n=5050$ people). Patients with chronic, refractory, and high risk diseases such as cancer, chronic respiratory disorders, spinal cord injury, congestive heart failure, hypothyroidism, multiple sclerosis (MS), history of psychological disorder diagnosed before the onset of DM, experience of accidents (such as death of family members) in the previous 6 months, drug and alcohol abuse, and infectious diseases with long-term treatment such as tuberculosis (TB) and brucellosis, and also children and teenagers younger than 13 years of age were excluded from the statistical population (it should be noted that the age range of patients referring to the center was 3 months-96 years). Therefore, the statistical population of this study including all patients with the study inclusion criteria amounted to 525 individuals. The sample volume was calculated as 222 individuals by considering this population and using Cochran's formula. The participants were selected from this population via simple random sampling. Ultimately, 194 questionnaires were completed and returned for analysis.

The researchers visited the diabetes center of the university, selected the subjects randomly based on the patient list, and explained the goal of the study to them. Subjects who provided an informed consent were enrolled in the study. Specialized psychological interviews were conducted with the selected 
individuals based on the Diagnostic and Statistical Manual of Mental Disorders, Fifth Edition (DSM-V) to investigate the presence and severity of some disorders such as anxiety and personality disorders. Then, some of the studied variables, such as duration of disease and type of treatment, were obtained from their medical record and written in a checklist designed for this purpose. Subsequently, the Beck Depression Inventory (BDI) was distributed among patients and they were asked to circle the number of the sentence which better described their current status with patience and without providing their name. They were assured of the confidentiality of their personal information. It was also stressed that from among each group of sentences, only one sentence should be selected. The collected data were analyzed using chi-square test and ANOVA in SPSS software (version 16, SPSS Inc., Chicago, IL, USA).

BDI was developed for the first time in the year 1961 by Beck et al. and underwent a major revision in the year 1996 in order to cover a wide range of symptoms and for better coordination with the diagnosis criteria of DSM-IV. In the revised form (BDI-II), in order to reflect symptoms that are accompanied with more severe depression (such as anxiety, sense of lack of value, concentration difficulties, and energy loss), 4 articles were changed. Moreover, in order to show the decrease in appetite and sleep, 2 articles were revised. Furthermore, the texts or sentences structure of many other articles were changed. Comparison between BDI and BDIII shows that respondents confirm one or two symptoms more frequently in the BDI-II form than the BDI and respondents with higher depression severity confirm symptoms or articles more than those with lower depression severity. Despite relatively higher scores in BDI-II, there is, in general, a high correlation between these two forms. Thus, with some caution, it can be said that BDI-II is comparable with its previous form and the results of many studies conducted with BDI can be generalized to BDI-II (15).

The BDI is a self-report inventory and $\mathrm{t}$ is composed of a 21 items that completed in 5 to 10 minutes. The inventory is composed of 21 articles related to different symptoms which are scored on a four-point scale ranging from 0 to 3 . These articles are related to fields such as sadness, pessimism, sense of failure and incapability, sense of guilt, sleep disorder, loss of appetite, and self-hatred.

\section{Results}

The total number of participants was 194 individuals with average age of $53.07 \pm 11.84$ years in the range of 21 to 96 years. In addition, $50.5 \%$ of the studied patients with DM were women and $97.4 \%$ were married. Among the subjects, $26.3 \%$ were illiterate, $42.3 \%$ had primary school education, $20.1 \%$ had high school diploma, and $11.3 \%$ have university degrees.

Moreover, $41.8 \%, 23.2 \%, 18.6 \%, 13.9 \%$, and $2.6 \%$ of the participants were homemakers, employed, self-employed, retired, and farmers, respectively. In terms of the type of treatment, $43.8 \%$ of subjects used tablets, $39.2 \%$ used insulin and tablets, and $17 \%$ only used insulin. The average depression score of the participants was $11.61 \pm 6.9$ and their average duration of awareness of their condition was $6.93 \pm 3.47$ years.

Table 1: Level of significance of results of one-way analysis of variance for the comparison of age and duration of awareness of the disease in patients with diabetes based on different levels of depression severity

\begin{tabular}{ccccccc}
\hline \multirow{2}{*}{ Variable } & \multirow{2}{*}{ Mean (SD) } & \multicolumn{4}{c}{ Depression } & \multirow{2}{*}{ P-value } \\
\cline { 3 - 6 } & Normal & Mild & Moderate & Severe & \\
\hline Age (year) & $53.07(11.84)$ & $47.5(8.84)$ & $62.4(6.03)$ & $74.2(11.78)$ & $57.5(6.35)$ & $\mathrm{P}<0.001$ \\
\hline $\begin{array}{c}\text { Duration of awareness of } \\
\text { the disease (year) }\end{array}$ & $6.93(3.47)$ & $5.84(2.89)$ & $8.96(3.74)$ & $10.1(2.94)$ & $8.5(1.73)$ & $\mathrm{P}<0.001$ \\
\hline
\end{tabular}


In this study, $67 \%$ of patients did not have depression or had the minimum severity of depression, $24.7 \%$ had mild depression, $6.2 \%$ had moderate depression, and $2.1 \%$ had severe depression. Results of ANOVA showed a significant difference in average age and duration of awareness of the disease of patients with DM based on different levels of depression severity $(\mathrm{P}<0.001)$ (Table 1).

Table 2: Paired comparison of age and duration of awareness of the disease in patients with different levels of depression severity

\begin{tabular}{cccccc}
\hline \multirow{2}{*}{ Variable } & $\begin{array}{c}\text { Depression } \\
\text { severity }\end{array}$ & $\begin{array}{c}\text { Compared } \\
\text { with }\end{array}$ & $\begin{array}{c}\text { Mean } \\
\text { difference }\end{array}$ & $\begin{array}{c}\text { Standard } \\
\text { error }\end{array}$ & P-value \\
\hline \multirow{3}{*}{ Age } & $\begin{array}{c}\text { Without } \\
\text { depression }\end{array}$ & Mild & -14.86 & 1.42 & $\mathrm{P}<0.001$ \\
\cline { 2 - 6 } & Mild & Moderate & -26.7 & 2.54 & $\mathrm{P}<0.001$ \\
\cline { 2 - 6 } & Moderate & Severe & 16.7 & 4.85 & $\mathrm{P}=0.004$ \\
\hline \multirow{2}{*}{$\begin{array}{c}\text { Duration of awareness } \\
\text { of the disease }\end{array}$} & $\begin{array}{c}\text { Without } \\
\text { depression }\end{array}$ & Mild & -3.12 & 0.52 & $\mathrm{P}<0.001$ \\
\cline { 3 - 6 } & & Moderate & -4.24 & 0.94 & $\mathrm{P}<0.001$ \\
\hline
\end{tabular}

To study the difference between groups, Tukey's post hoc test was used. The results of Tukey's test showed a significant difference between the average age of subjects without depression and those with mild or moderate depression $(\mathrm{P}<0.001)$, and average depression score of subjects with moderate depression and those with severe depression $(\mathrm{P}=0.004)$. Furthermore, the duration of awareness of the illness in participants without depression had a statistically significant difference with that in participants with mild or moderate depression $(\mathrm{P}<0.001)$ (Table 2).

Table 3: Frequency distribution of depression in the studied patients with diabetes

\begin{tabular}{|c|c|c|c|c|c|c|c|c|c|}
\hline \multirow{2}{*}{ Variable } & \multirow{2}{*}{ Group } & \multirow{2}{*}{ Number } & \multirow{2}{*}{ Percentage } & \multicolumn{4}{|c|}{ Depression } & \multirow{2}{*}{ Total } & \multirow{2}{*}{$\mathrm{P}$-value } \\
\hline & & & & Normal & Mild & Moderate & Severe & & \\
\hline \multirow{2}{*}{ Sex } & Male & 96 & 49.5 & 50.8 & 39.6 & 58.3 & 100 & 49.5 & \multirow{2}{*}{$\mathrm{P}=0.093$} \\
\hline & Female & 98 & 50.5 & 49.2 & 60.4 & 41.7 & 0 & 50.5 & \\
\hline \multirow{2}{*}{$\begin{array}{c}\text { Marital } \\
\text { status }\end{array}$} & Single & 5 & 2.6 & 3.1 & 2.1 & 0 & 0 & 2.6 & \multirow{2}{*}{$\mathrm{P}=0.89$} \\
\hline & Married & 189 & 97.4 & 96.9 & 97.9 & 100 & 100 & 97.4 & \\
\hline \multirow{4}{*}{ Education } & Illiterate & 51 & 26.3 & 16.2 & 41.7 & 83.3 & 0 & 26.3 & \multirow{4}{*}{$\mathrm{P}<0.001$} \\
\hline & Primary school & 82 & 42.3 & 44.6 & 43.8 & 8.3 & 50 & 42.3 & \\
\hline & High school & 39 & 20.1 & 25.4 & 6.3 & 8.3 & 50 & 20.1 & \\
\hline & University & 22 & 11.3 & 13.8 & 8.3 & 0 & 0 & 11.3 & \\
\hline \multirow{5}{*}{ Occupation } & Employee & 45 & 23.2 & 30 & 8.3 & 0 & 50 & 23.2 & \multirow{5}{*}{$\mathrm{P}<0.006$} \\
\hline & Farmer & 5 & 2.6 & 3.1 & 2.1 & 0 & 0 & 2.6 & \\
\hline & Homemaker & 81 & 41.8 & 36.9 & 58.3 & 41.7 & 0 & 41.8 & \\
\hline & Self-employed & 36 & 18.6 & 20 & 12.5 & 33.3 & 0 & 18.6 & \\
\hline & Retired & 27 & 13.9 & 10 & 18.8 & 25 & 50 & 13.9 & \\
\hline \multirow{3}{*}{$\begin{array}{c}\text { Type of } \\
\text { treatment }\end{array}$} & Insulin & 76 & 39.2 & 36.2 & 41.7 & 58.3 & 50 & 39.2 & \multirow{3}{*}{$\mathrm{P}=0.022$} \\
\hline & Tablet & 85 & 43.8 & 51.5 & 29.2 & 16.7 & 50 & 43.8 & \\
\hline & Insulin + tablet & 33 & 17 & 12.3 & 29.2 & 25 & 0 & 17 & \\
\hline
\end{tabular}

Different severities of depression were compared in the present study based on sex, marital status, and level of education, occupation, and type of treatment. The frequency of moderate and severe depression was higher in men and the frequency of mild 
depression was higher in women. However, this difference was not statistically significant $(\mathrm{P}=$ 0.093). In addition, no significant difference was observed among single and married individuals in terms of the prevalence of different levels of depression severity ( $\mathrm{P}=$ $0.89)$. The number of individuals without depression and with mild depression was higher among subjects with primary school education. The number of individuals with moderate depression was higher among illiterate participants. Moreover, the number of subjects with severe depression was higher among patients with primary and high school education. There was no case of moderate or severe depression among subjects with Discussion

$\mathrm{DM}$ is a chronic disease without a definitive treatment, but it is controllable. If not controlled, it affects many organs especially vital organs such as the heart, brain, and kidneys. These effects result in sensory and locomotion disabilities which limit the daily activities of the individual and lead to a sense of uselessness and depression (16). In this study, the prevalence of depression in patients with DM using BDI was estimated at 33\%. Among the participants, $24.7 \%, 6.2 \%$, and $2.1 \%$, respectively, had mild, moderate, and severe depression. The prevalence of depression in different studies has varied based on the population under study and measurement tool used. For example, the prevalence of depression among patients with DM in the studies by Larijani (17), Taziki (18), Nejati Safa (19), Mazloumi (20), Mahmodi (21), Nouwen (22) was $41.9 \%$ (based on BDI), $40.6 \%$ (moderate to severe depression), 28\% (clinical depression), 64\%, $77 \%, 41 \%$, and $24 \%$ (22), respectively. Furthermore, in the study by Larijani, the prevalence of major depressive disorder (MDD), based on clinical interview and DSMIV criteria, was $23.7 \%$ and the prevalence of dysthymia was $9.3 \%$ (17). It appears that this difference in in prevalence of depression among diabetic patients is due to geographic university degrees. This relationship was statistically significant $(\mathrm{P}<0.001)$.

The highest frequency of moderate depression was observed among homemakers and the highest frequency of individuals with moderate and severe depression was observed among employees and retired subjects $(\mathrm{P}=$ 0.006).

Furthermore, the highest frequency of moderate depression was observed among patients under treatment with insulin and the highest frequency of severe depression was observed in patients under simultaneous treatment with insulin and tablets $(\mathrm{P}=0.022)$ (Table 3).

and demographic differences and the different measurement tools used. In addition, other factors influence depression caused by diseases which have not be considered in the present study and similar studies. Among these factors are income which is an important factor in procuring medicine, family support, and quality and quantity of health and treatment services (16).

In the present study, a significant relationship was observed between average depression score and age; with increasing of age, the average score of depression also increased. There was a significant difference between frequency of different severities of depression based on age; the highest average age was observed among patients with moderate depression (74.2 \pm 11.75 years) and the lowest average age was observed among patients without depression (47.6 \pm 8.89 years).

In study by Larijani, the highest prevalence of MDD and dysthymia was reported in the age groups of 31-39 years and above 60 years, respectively (17). Nevertheless, there was no significant relationship between depression and age in patients with DM studied by Ranjbar (23). The relationship between age and onset of depression symptoms is not well understood. The higher prevalence of depression of the elderly may be due to other reasons such as social isolation, limitation of resources and facilities, and physical inability 
(24). Not all studies have reported a high prevalence of depression in adults. Egede showed a $4.5 \%$ prevalence of depression in individuals with DM aged above 65 years, which was lower compared to other age groups (25). However, the tool used in this study was related to severe depression disorders (25). In the study by Mahmoudi, the prevalence of depression in the age group of above 40 years was lower than the age group of younger than 40 years both in diabetes and healthy groups. With the increasing of age, the probability of incidence of depression is increased and this probability increases even further in the presence of DM $(78.9 \%$ in the diabetic group compared to $42.9 \%$ in the healthy group) (21).

In the present study, the frequency of different severities of depression did not differ significantly among women and men. In this respect, the results of the present study are in line with that of the studies by Taziki (18) and Ranjbar (23). Nevertheless, in the studies by Larijani (17), Mazloumi (20), Sahota (26), Palinkas (27), and Papadopoulos (28), the rate of depression in women with DM was higher than men. This may be due to women's limitation in social relationships due to inabilities stemmed from DM and also the special circumstances of women in terms of stressful situations in the family. Furthermore, the frequency of different severities of depression had a significant difference based on years since the onset of disease. The highest and lowest average years since disease diagnosis were related to patients with moderate depression $(10.08 \pm 2.94$ years $)$ and patients without depression $(5.82 \pm 2.95$ years), respectively. These findings are in agreement with that of the studies by Taziki (18) and Taheri (29). Mahmoudi reported a 90.7\% rate of depression among patients with more than 10 years history of DM, but a $73.9 \%$ rate among patients with less than 10 years history of DM (21). Moreover, severe depression in diabetic patients with more than 10 years history of DM was $28.2 \%$ higher than patients with less than 10 years history of DM; however, this difference was not statistically significant. It appears that the higher severity and frequency of depression, which increase with the increase in number of years since the diagnosis of DM, are related to the emergence of disease complications with the passing of time.

The results of the present study showed a significant difference between the frequencies of different severities of depression in patients with DM based on occupation. The highest frequency in different depression severities was related to homemakers. In the study by Ranjbar, a higher percentage of depression was observed in unemployed individuals compared to working individuals (23). The results the study by Friis showed that depression and unemployment are correlated and occupational status is a more effective factor in the onset of depression compared to DM, education, DM type, blood sugar level, and treatment type (30).

In the present study, the frequency of different severities of depression significantly differed in the participants based on education. The highest frequency of moderate to severe depression was among illiterate subjects and the highest frequency of individuals without depression was in the group with university education. Thus, the results of the present study are in agreement with that of the studies by Mazloumi (20), Taheri (29), and Ranjbar (23). Some researchers have attributed the higher depression rate among individuals with lower education to their lower income (28). Although it appears that there are causes other than economic factors, such as cultural factors and higher knowledge about DM and its more efficient management, for the lower depression in patients with higher education.

The results of the present study showed that frequencies of different severities of depression among single and married individuals did not have a significant difference. This finding was in line with that of the study by Ranjbar (23). However, it was not in agreement with the results of the studies by Moayedi (31) and Taheri (29), who 
reported a higher rate of depression among married individuals with DM.

The results of the present study showed that the frequencies of different severities of depression based on type of treatment had a significant difference; the highest number of individuals with severe depression used insulin and tablet for blood sugar control. The highest number of participants with moderate depression was among those under treatment with insulin. This result was in line with that of the study by Noh (32), but was not in accordance with that of the study by Ranjbar (23) who showed that there is no relationship between type of treatment and depression. Lack of hope of blood sugar control with edible drugs or non-pharmacological methods, such as diet and sports, and the necessity of using insulin causes problems such as procurement, storage, injection method, fear of injection, lack of ability to inject the exact dose, and monetary funds which may, in turn, cause physical and mental problems (33).

\section{Conclusion}

$\mathrm{DM}$, due to its chronic nature and long-term complications, which decrease individuals' ability of adjustment, causes behavioral complications. Stress, due to affliction to a chronic disease without the possibility of a definitive treatment, is the grounds for depression. Depression in individuals with DM is related to factors such as age, occupation, and level of education. Therefore, in patients with DM, in addition to controlling their blood sugar level, psychological problems should also be considered. Furthermore, by providing the necessary training on the nature of the disease and its management and forming support groups, measures can be taken for the prevention or reduction of its comorbidities.

\section{Acknowledgement}

The authors wish to thank all individuals who helped in this study, including the Research Deputy, Head of Research, staff of the Diabetes Center of Rafsanjan University of
Medical Sciences, and all participants who filled the questionnaires with patience.

Conflict of interests: None declared.

\section{References}

1. World health Organization. Global report on diabetes. World health Organization, Geneva, Switzerland; 2016. Available from: http://apps.who.int/iris/bitstream/10665/20487 1/1/9789241565257_eng.pdf.

2. Surrena H. Handbook for Brunner \& Suddarth's textbook of medical-surgical nursing. $12^{\text {th }}$ ed. Philadelphia, United States: Lippincott Williams \& Wilkins; 2010.

3. Faulkner MS. Quality of life for adolescents with type 1 diabetes: parental and youth perspectives. Pediatr Nurs 2003; 29(5):362-8.

4. Holt T, Kumar S. ABC of diabetes. $6^{\text {th }}$ ed. Hoboken, New Jersey, United States: John Wiley \& Sons, Inc; 2013

5. Askarishahi M, Malaki Moghadam $\mathrm{H}$, Fallahzade H, Lotfi MH, Afkhami-Ardekani M. Trend analysis of the rate of mortality due to diabetes mellitus in Iran during the period of 2003-2010: A join point regression analysis. Journal of Occupational Health and Epidemiology 2014; 3(2):112-6.

6. Funnell MM, Anderson RM. Empowerment and self-management of diabetes. Clin Diabetes 2004; 22(3):123-7.

7. Lustman PJ, Griffith LS, Clouse RE, Freedland $\mathrm{KE}$, Eisen SA, Rubin EH, et al. Effects of nortriptyline on depression and glycemic control in diabetes: results of a double-blind, placebo-controlled trial. Psychosom Med 1997; 59(3):241-50.

8. Ludman EJ, Katon W, Russo J, Von Korff M, Simon G, Ciechanowski P, et al. Depression and diabetes symptom burden. Gen Hosp Psychiatry 2004; 26(6):430-6.

9. Fleming GA, Jhee SS, Coniff RF, Riordan HJ, Marphy MF, kurts NM, et al. Optimizing therapeutic developments in diabetes. $1^{\text {st }}$ ed. New York, United States: Greenwich Medical Media; 1999.

10. Lishman WA. Organic psychiatry: The psychological consequencesof cerebral disorder. $3^{\text {rd }}$ ed. Hoboken, New Jersey, United States: John Wiley \& Sons, Inc; 1998.

11. Husaini BA, Hull PC, Sherkat DE, Emerson JS, Overton MT, Craun C, et al. Diabetes depression, and healthcare utilization among African Americans in primary care. J Natl Med Assoc 2004; 96(4):476-84. 
12. Abdoli S, Mardanian L, Mirzaei M. How public perceive diabetes: A qualitative study. Iran J Nurs Midwifery Res 2012; 17(5):370-4.

13. Peyrot M, Rubin RR. Levels and risks of depression and anxiety symptomatology among diabetic adults. Diabetes Care 1997; 20(4):585-90.

14. Sevinock L, Guney E, Uslu A, Baklaci F. Depression in a sample of Turkish type 2 diabetes patients. Eur Psychiatry 2001; 16(4):229-31.

15. Rajabi Gh. Psychometric properties of back depression inventory short from items (BDI13). Psychological characters of Beck depression inventory, Short form. Developmental Psychology 2005; 1(4):291-8.

16. Jeeva F, Dickens Ch, Coventry P, Bundy Ch, Davies L. Is treatment of depression costeffective in people with diabetes? A systematic review of the economic evidence. Int J Technol Assess Health Care 2013; 29(4):384-91.

17. Larijani B, Khoramshahee M, khaliligorgani M, Bandarian F, Akhondzadeh Sh. Association of depression and diabetes in the doctor shariati diabetes clinic and iranian diabetes association. J Diabetes Metab Disord 2004; 3(1):77-82.

18. Taziki SA, Bazrafsan HR, Behnampour N, Paviz M. Relationship between depressive's symptoms and diabetes. Journal of Gorgan University of Medical Sciences 2001; 3(2):5964.

19. Nejati Safa A, Larijani B, Shariati B, Amini H, Rezagholizadeh A. Depression, quality of life and glycemic control in patients with diabetes. J Diabetes Metab Disord 2007; 7(2):195-204.

20. Mazloomi SS, Mirzaee A, Mahmoodi S. Study of depression prevalence in the patients with type II diabetes referring to Yazd Diabetes Research Center in 2008. Tolooe Behdasht 2008; 7(1-2):30-5.

21. Mahmoodi A, Sharifi A. Comparison frequency and factors associated with depression in diabetics and non diabetics patients. Journal of Nursing and Midwifery Urmia University of Medical Sciences 2008; 6(2):88-93.

22. Nouwen A, Winkley K, Twisk J, Lloyd CE, Peyrot M, Ismail K, et al. Type 2 diabetes mellitus as a risk factor for the onset of depression: a systematic review and metaanalysis. Diabetologia 2010; 53(12):2480-6.
23. Ranjbar KH, Sharif F, Dezhbakhsh T. Frequency and severity of depression in diabetic adults using tablet and insulin. Medical Journal of Hormozgan University 2007; 10(4):363-9.

24. Swenson CJ, Baxter J, Shetterly SM, Scarbro SL, Hamman RF. Depressive symptoms in Hispanic and non-Hispanic white rural elderly: the san luis valley health and aging study. Am J Epidemiol 2000; 152(11):1048-55.

25. Egede LE, Zheng D, Simpson K. Comorbid depression is associated with increased health care use and expenditures in individuals with diabetes. Diabetes Care 2002; 25(3):464-70.

26. Sahota PK, Knowler WC, Looker HC. Depression, diabetes, and glycemic control in an American Indian community. J Clin Psychiatry 2008; 69(5):800-9.

27. Palinkas LA, Barrett-Connor E, Wingard DL. Type 2 diabetes and depressive symptoms in older adults: a population-based study. Diabet Med 1991; 8(6):532-9.

28. Papadopoulos AA, Kontodimopoulos N, Frydas A, Ikonomakis E, Niakas D. Predictors of health-related quality of life in type II diabetic patients in Greece. BMC Public Health 2007; 7:186.

29. Taheri N, Hojjati H, Mousavi M, Afra A, Dehghan B. The survey of anxiety and depression prevalence in diabetic patient referred to Abadan Taleghani and Khorramshahr Valiasr hospitals in 2011. J Diabetes Nurs 2014; 1(2):21-31.

30. Friis R, Nanjundappa G. Diabetes, depression and employment status. Soc Sci Med 1986; 23(5):471-5.

31. Moayedi F, Zare S, Nikbakht A. Anxiety and depression in diabetic patient referred to Bandar Abbas diabetes clinic. Hormozgan Medical Journal 2015; 18(1):65-71.

32. Noh JH, Park JK, Lee HJ, Kwon SK, Lee SH, Park JH, et al. Depressive symptoms of type 2 diabetics treated with insulin compared to diabetics taking oral anti-diabetic drugs: a Korean study. Diabetes Res Clin Pract 2005; 69(3):243-8.

33. Besharati M. The survey of effective factors on barriers to initiating insulin therapy in diabetic patients referred to diabetic center of Yazd in 2015 [MD thesis]. Rafsanjan: Rafsanjan University of Medical Sciences; 2016. 